\title{
Patterns of gene amplification in gastrointestinal stromal tumors (GIST)
}

Luigi Tornillo ${ }^{1}$, Giacomo Duchini ${ }^{1}$, Vincenza Carafa ${ }^{1}$, Alessandro Lugli $^{1}$, Stefan Dirnhofer ${ }^{1}$, Dolores Di Vizio ${ }^{2}$, Amedeo Boscaino ${ }^{3}$, Rosanna Russo ${ }^{4}$, Coya Tapia $^{1}$, Regine Schneider-Stock ${ }^{5}$, Guido Sauter ${ }^{1}$, Luigi Insabato ${ }^{2}$ and Luigi M Terracciano ${ }^{1,2}$

${ }^{1}$ Institute of Pathology, University of Basel, Switzerland; ${ }^{2}$ Department of Biomorphological and Functional Sciences, University 'Federico II' of Naples, Italy; ${ }^{3}$ Operative Unit of Pathology, 'Antonio Cardarelli' Hospital, Naples, Italy; ${ }^{4}$ Operative Unit of Pathology, 'San Leonardo' Hospital, Salerno, Italy and ${ }^{5}$ Department of Pathology, Otto-von-Guericke University, Magdeburg, Germany

\begin{abstract}
Gastrointestinal stromal tumors (GIST) are the most common primary mesenchymal tumors of the gastrointestinal tract (GIT). They represent a wide clinico-pathological spectrum of tumors. No single histological or clinical parameter can predict the prognosis while the response to therapy is related to the type of KIT or PDGFRA mutation. Cytogenetic and CGH studies have identified frequent gross chromosomal aberrations but the target genes of these changes are unknown. To determine whether known oncogenes take part in genomic rearrangements and to investigate the potential clinical significance of their amplifications, nine known oncogenes (CMYC, MDM2, GLI1, CDK4, HER2, EGFR1, CCND1, FGF3, EMS) were analyzed by fluorescent in situ hybridization (FISH) on a tissue microarray (TMA) containing 94 primary GIST. Clinical followup information was available for 57 of these patients. Amplification was found for CMYC in three of 90 (3.3\%), for MDM2 in five of 94 (5.3\%), for EGFR1 in five of $94(5.3 \%)$, and for CCND1 in seven of 79 (8.9\%) evaluable cases. No amplifications were seen for HER2, GLI1, CDK4, FGF3, and EMS. Amplifications of MDM2 and CCND1 were associated with clinical and histological malignancy. In conclusion, our data show that gene amplification does occur in a subset of GIST. Identification of MDM2/CCND1 amplification may represent another molecular feature that could help in the evaluation of the behavior of GISTs.
\end{abstract}

Laboratory Investigation (2005) 85, 921-931. doi:10.1038/labinvest.3700284; Published online 2 May 2005

Keywords: GIST; FISH; TMA; amplification; MDM2; HER2; EGFR1; CCND1

Gastrointestinal stromal tumors (GIST) occur in about 20/100 000 individuals per year. Despite their overall rarity, GIST are the most common primary mesenchymal tumors of the gastrointestinal tract (GIT). ${ }^{1-5}$ They share morphologic, immunophenotypic and genetic characteristics with the interstitial cells of Cajal (ICCs), the pacemaker cells of the gut $^{1,5-7}$ from which they are thought to be derived. Both ICCs and GISTs show diffuse strong KIT (CD117) protein expression, ${ }^{1,4-6,8,9}$ which is considered a diagnostic hallmark of GIST. ${ }^{4,10}$ Since KIT is one of the targets for the tyrosine kinase inhibitor Imatinib mesylate, successful treatments of GIST with this drug have recently been reported. ${ }^{11-13}$

Correspondence: Dr L Tornillo, MD, Institute of Pathology, University of Basel, Schönbeinstrasse 40, CH-4003 Basel, Switzerland.

E-mail: tornillol@uhbs.ch

Received 9 September 2004; revised 21 March 2005; accepted 22 March 2005; published online 2 May 2005
Moreover, it has been shown that some GISTs may show mutations in the gene coding for plateletderived-growth factor alpha (PDGFRA). Tumors expressing KIT or PDGFRA oncoproteins were indistinguishable with respect to activation of downstream signaling intermediates and cytogenetic changes associated with tumor progression. KIT and PDGFRA mutations appear to be alternative and mutually exclusive oncogenic mechanisms in GISTs. ${ }^{14,15}$ From a clinico-pathological point of view GISTs represent a spectrum of tumors including very low-risk, low-risk, intermediate-risk and high-risk variants. However, no single morphologic, immunohistochemical or genetic feature allows to predict the behavior of an individual tumor. ${ }^{10,16-27}$ Some authors suggested that presence of KIT mutations is associated with malignancy; ${ }^{21,28,29}$ however, these results have not been confirmed. ${ }^{25,30}$ Recently, it has been shown that the type of KIT and PDGFRA mutation may predict the response to therapy with Imatinib. ${ }^{31,32}$ Other molecular alterations have been 
reported in GIST. Comparative genomic hybridization (CGH) and fluorescent in situ hybridization (FISH) studies have identified numerous chromosomal regions with frequent losses such as $1 \mathrm{p}, 9 \mathrm{p}, 11$, $13 q, 14 q, 15 q, 19 q$, or $22 q$ or over-representations including 5p, 8q, $17 \mathrm{q}$, and 20q. ${ }^{2,333-39}$ Little is known about the target genes of these alterations and their possible associations with clinical behavior. In particular, information is lacking on the role of individual oncogenes and the prevalence of their amplifications in GIST.

In an attempt to investigate the prevalence and clinical significance of gene amplifications in GIST, we brought well-documented cases of GIST of 94 patients in a tissue microarray (TMA) format as previously described. ${ }^{40}$ In this procedure hundreds of minute tissue samples (diameter: $0.6 \mathrm{~mm}$ ) can be simultaneously analyzed on one microscope glass slide by all types of in situ techniques. Nine different oncogenes (CMYC, MDM2, GLI1, CDK4, HER2, EGFR1, CCND1, FGF3, and EMS) were analyzed by FISH. Apart for EGFR1, based on our previous experience (unpublished data), we decided not to perform additional immunohistochemical stainings for the products of these oncogenes. Our data may suggest that oncogene amplifications occur at significant frequency in GIST.

\section{Materials and methods}

\section{Patients}

All tumors were retrieved from the files of the Institutes of Pathology of the Universities of Basel and of Naples, 'Federico II' and of the Hospitals 'Antonio Cardarelli' of Naples and 'S. Leonardo' of Salerno. Two pathologists (LT and LI) re-examined representative slides of each tumor. The diagnosis of GIST was confirmed in case a mesenchymal spindle cell or epithelioid tumor of the GIT showed unequivocal positivity for CD117. ${ }^{41}$ In all, 100 tumors (94 primary tumors and six metastasis) of 94 patients met these criteria and were included in this study. The 94 GIST patients comprised 50 males and 44 females with a mean age of 61 years (range 26-91, SD 14). Tumor localization was the stomach in 56 $(56 \%)$, small bowel in $27(27 \%)$, mesentery in six $(6 \%)$, duodenum in four $(4 \%)$, rectum in three $(3 \%)$, esophagus in one $(1 \%)$, colon in one $(1 \%)$, abdominal soft tissues in one $(1 \%)$ and pancreas in one (1\%). The mean tumor size was $67.3 \mathrm{~mm}$ (range $5-250)$. A total of 37 tumors $(37 \%)$ were $<50 \mathrm{~mm}$ in diameter.

\section{Assessment of Behavior}

To distinguish tumors of different degrees or probabilities of malignancies we first reviewed medical charts that were available from 59 of 94 patients $(63 \%)$. Of these 59 patients, 11 (19\%) died of the disease, and $12(20 \%)$ were alive with recurrent/metastatic disease. These 23 tumors were considered clinically malignant.

Additional 35 patients (61\%) were alive without disease, and one $(2 \%)$ died of other causes. As the follow-up of these patients was generally not long enough to fully exclude malignancy (median 23 months), these tumors were not classified according to their clinical information. Together with these, 35 primary tumors for which clinical data were lacking were classified into the following categories: malignant, high risk, intermediate risk, low risk and very low risk of malignancy. Tumors were considered malignant if the presence of metastasis at time of operation or later was observed $(n=14)$; tumors of any size and with mitotic index (MI) $>10 / 50 \mathrm{HPF}$ or tumors $>10 \mathrm{~cm}$ in size and with any MI or tumors $5-10 \mathrm{~cm}$ in size and MI $>5 / 50 \mathrm{HPF}$ were considered as high risk $(n=12)$; tumors $<5 \mathrm{~cm}$ in size and with MI 6-10/50 HPF or tumors $5-10 \mathrm{~cm}$ in size and with $\mathrm{MI} \leq 5 / 50 \mathrm{HPF}$ were considered intermediate risk $(n=19)$; tumors with diameter between 2 and $5 \mathrm{~cm}$ and $\mathrm{MI} \leq 5 / 50 \mathrm{HPF}$ were considered as low risk $(n=21)$; tumors with diameter $<2 \mathrm{~cm}$ and $\mathrm{MI} \leq 5 / 50$ HPF were considered as very low risk $(n=5) .{ }^{4}$ The characteristics of our series are shown in Table 1.

\section{TMA Construction}

Representative areas of each tumor were identified on a HE-stained slide. One sample each with a diameter of $0.6 \mathrm{~mm}$ was taken from 147 tissue blocks and placed in our TMA using a semiautomated tissue arraying device. The tissue collection included 94 primary GIST, six GIST metastases and a control section composed of 33 leiomyomas, seven leiomyosarcomas, and two schwannomas of the gastrointestinal tract as well as five samples of normal gastric mucosa (Figure 1).

\section{FISH}

Five micrometer sections were made from TMA blocks using an adhesive-coated slide system (Instrumedics Inc., Hackensack, NJ, USA). Sections were treated according to the Paraffin Pretreatment Reagent Kit protocol before hybridization (Vysis, IL, USA). FISH was performed with Spectrum Orange-

Table 1 Evaluation of relative risk of malignant behavior

\begin{tabular}{lc}
\hline Relative risk & $\mathrm{N}(\%)$ \\
\hline Very low risk & $5(5.3)$ \\
Low risk & $21(22.3)$ \\
Intermediate risk & $19(20.2)$ \\
High risk & $12(12.8)$ \\
Malignant & $37(39.3)$ \\
Total & $94(100)$
\end{tabular}




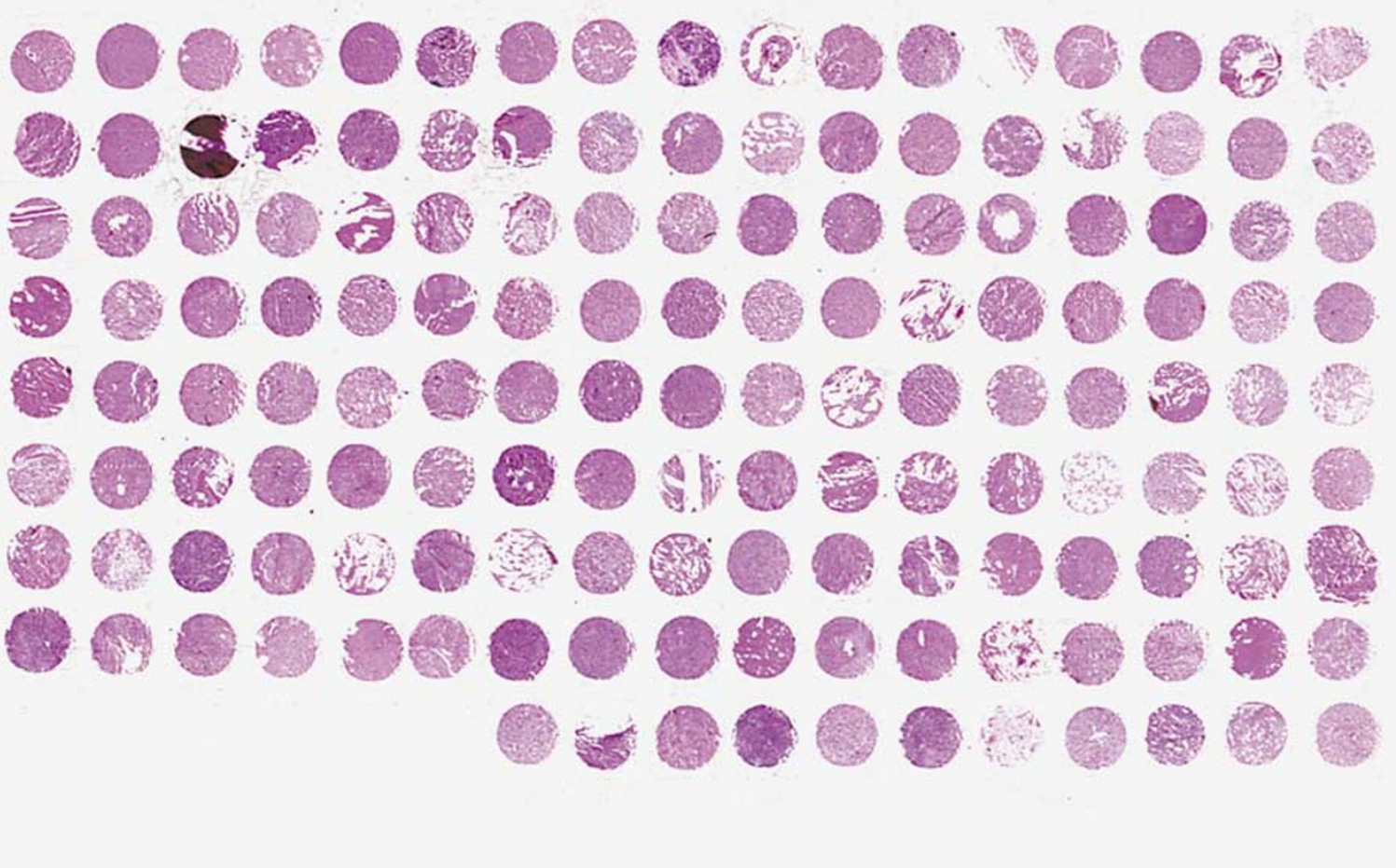

Figure 1 Tissue array for FISH analysis. Overview of hematoxylin- and eosin-stained sections from one block containing 147 specimens.

labeled CMYC, MDM2, GLI1, CDK4, HER2, EGFR1, Cyclin D1, FGF3, and EMS probes, each in combination with Spectrum Green-labeled centromere probes for the corresponding chromosomes ${ }^{8,12,17,7,11}$ as reference (Vysis, IL, USA). Hybridization and posthybridization washes were performed according to the 'LSI procedure' (Vysis, IL, USA). Slides were then counterstained with $125 \mathrm{ng} / \mathrm{ml}^{\prime}$,6-diamino-2phenylindole in antifade solution. The green and red signals were counted in 20 nuclei per tissue sample. Amplification was defined as a gene probe/ centromere probe ratio of $\geq 2.0$. To assess the samples for polisomy of the analyzed centromere probes, we first determined the average copy numbers of centromere probes in benign control tissues (smooth muscle and normal gastric epithelium). A tumor was then classified as polysomic for a chromosome if the average centromere copy number exceeded the average copy number detected in 10 normal control tissues plus 3 SD (Table 1). As positive controls we performed FISH analysis on sections of tissue with known amplifications.

\section{Immunohistochemistry}

Four micrometer thick sections of TMA blocks were transferred to an adhesive coated slide system (Instrumedics Inc., Hackensack, NJ, USA) supporting the cohesion of $0.6 \mathrm{~mm}$ array elements on glass. Standard indirect immunoperoxidase procedures were used for immunohistochemistry. After pretreatment with proteinase K (DAKO, Carpinteria, USA) monoclonal mouse antibody (dilution 1:50, DAKO Cytomation, Carpinteria, USA) was used for EGFR1 detection. A DAB chromogen was used. Nuclei were counterstained with hematoxylin.

For tumor and normal tissues the percentage of positive cells was estimated. Only membranous staining was considered positive in this setting.

\section{KIT Sequence Analysis}

Deparaffinization of the formalin-fixed tissues and DNA extraction were performed according to established protocols (Qiagen, Basel, Switzerland). The exons 9, 11, 13, and 17 of the KIT gene, where mutations were previously reported, were amplified using a seminested polymerase chain reaction approach. All exons were sequenced directly using Big Dye Terminators Cycle Sequencing Ready Reaction Kit (Applied Biosystems, Foster City, CA, USA). Primers designed for polymerase chain reaction and sequence reactions are listed below. Sequence products were analyzed on an ABI Prism 310 Genetic Analyzer (Applied Biosystems).

Exon 9

Forward 5-TCCTAGAGTAAGCCAGGGCTT-3

Reverse 5-TGGTAGACAGAGCCTAAACATCC-3

Nested forward 5-AGCCAGGGCTTTTGTTTTCT-3 


\section{Exon 11}

Forward 5-CCAGAGTGCTCTAATGACTG-3

Reverse 5-AGCCCCTGTTTCATACTGAC-3

Nested reverse 5-ACTCAGCCTGTTTCTGGGAAA CTC-3

Exon 13

Forward 5-GCTTGACATCAGTTTGCCAG-3 Reverse 5-AAAGGCAGCTTGGACACGGCTTTA-3 Nested forward 5-TGACATCAGTTTGCCAGTTG-3

Exon 17

Forward 5-TCCTTACTCATGGTCGGATC-3

Reverse 5-AAGAGACGAACTGTCAGGAC-3

Nested reverse 5-ACTGTCAAGCAGAGAATGGG-3

\section{Statistics}

Association of polisomies or amplifications with tumor phenotype and malignancy was investigated by a $\chi^{2}$ test with correction for continuity as appropriate. For this analysis, very low and low risk, tumor such as high risk and malignant tumors were considered as one group.

\section{Results}

\section{Gene Amplification}

The number of evaluable cases was 81 for HER2 (81\%), 94 for EGFR1 (94\%), 90 for CMYC (90\%), 79 for CCND1 (79\%), and 94 for MDM2 (94\%). Reasons for nonevaluable cases were insufficient hybridizations or a lack of tumor tissue on the TMA. A total of 20 amplifications were detected in 16 cases (four tumors had multiple amplifications). Clear cut amplifications $(2.0<$ ratio $\leq 5)$ were found for CMYC in three of $90(3.3 \%)$, for MDM2 $(4 \leq$ ratio $\leq 7)$ in five of $94(5.3 \%)$, for EGFR1 $(4 \leq$ ratio $\leq 7)$ in five of $94(5.3 \%)$, and for CCND1 $(4 \leq$ ratio $\leq 8)$ in seven of $79(7.7 \%)$ of evaluable cases (Figure 2). Coamplifications involved CCND1 and MDM2 in three cases and EGFR1 and CMYC in one case. Examples of amplified tumors are shown in Figure 2. No amplifications were observed for HER-2.
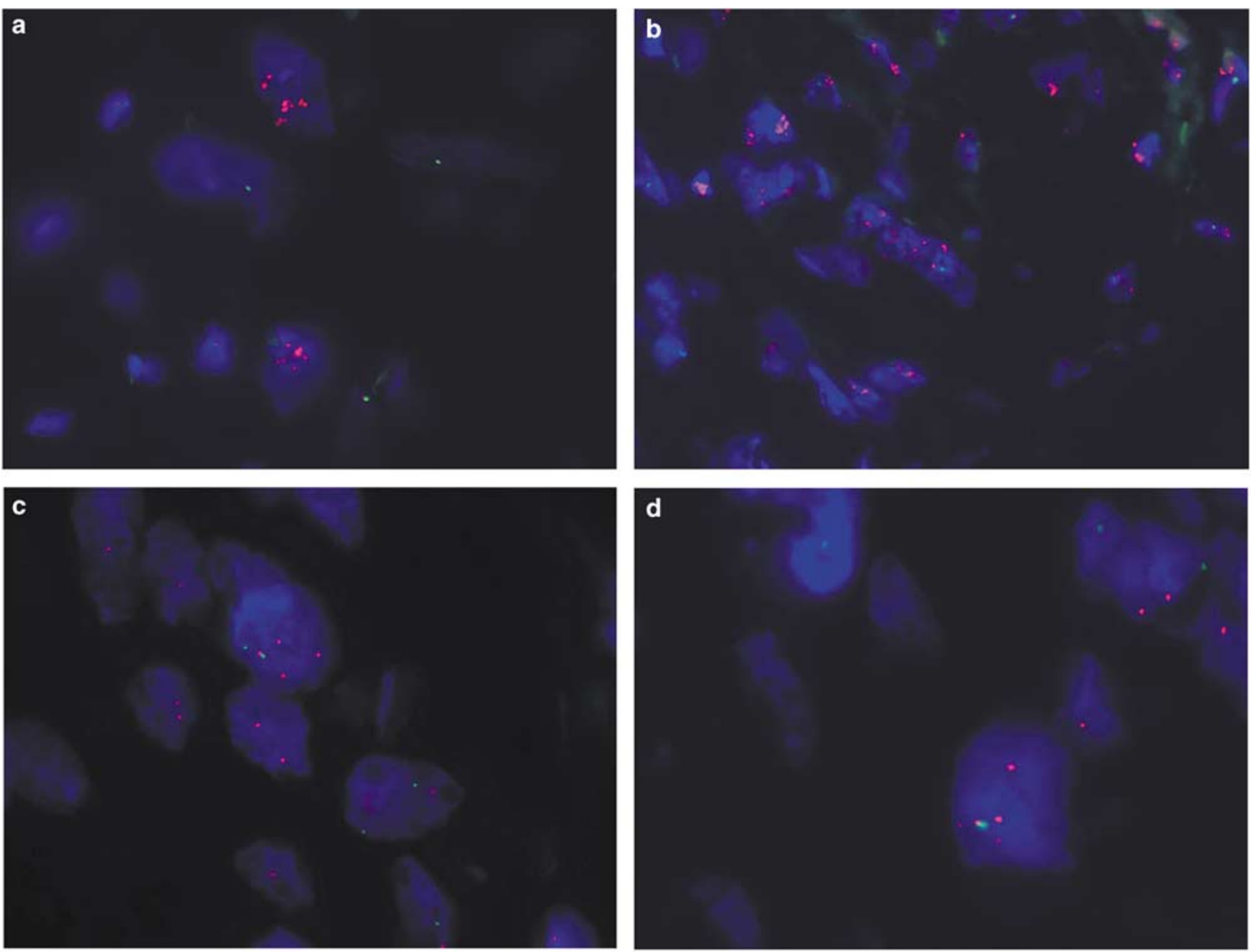

Figure 2 Examples of amplification of CCND1, MDM2, CMYC, and EGFR1. The red signals are from the gene probe, the green ones from the centromeric probe. There are at least two-fold red signals (sometimes in clusters). (a) CCND1, $\times 100(\mathbf{b})$ MDM2, $\times 100(\mathbf{c})$ CMYC, $\times 100($ d) EGFR1, × 100 . 
The presence of amplification was linked to malignancy (Table 2). Amplifications were seen in eight $(22 \%)$ of 37 malignant primary tumors, five $(42 \%)$ of 12 high-risk primary tumors, one $(6 \%)$ of 18 intermediate risk primary tumors, two $(10 \%)$ of 21 low-risk tumors. No amplification was found in very low-risk tumors. The analysis of individual genes revealed that CCND1 and MDM2 amplifications were detected only in high risk or malignant tumors while the other genes, which were only rarely amplified, showed no significant correlation with malignancy. In order to better define the state of the corresponding chromosomal regions (12q1314, 11q13-14) we also performed additional FISH analyses with probes for FGF3 (11q13), EMS1 (11q13), GLI1 (12q13), and CDK4 (12q14). However, all these genes failed to show any amplification. Interestingly, if very low and low-risk tumors formed one group and high risk and malignant tumors another group, the distribution of amplifica- tion reached statistical significance for CCND1 and MDM2 (Table 2). No significant association was seen between presence of gene amplification and histologic tumor type or tumor location.

Only occasional (three cases) low-level immunohistochemical positivity was observed for EGFR1, without any relationship with amplification or clinicopathologic parameters.

\section{Polisomies}

Between 83 and 94 tumors were interpretable for polisomy analysis. According to our definition, 22 tumors were found to be polisomic for at least one chromosome. Chromosome 17 (12 polisomies) was most frequently involved. Multiple polisomies were found in one tumor. No polisomy was observed for chromosomes 11 and 7. No association was observed between presence of polisomy and malignancy (Table 3) and as histologic tumor type or tumor location.

Table 2 Correlation of amplification with risk of malignant behavior

\begin{tabular}{|c|c|c|c|c|}
\hline Gene (cases assessed) & Low or very low risk & Intermediate & High-risk malignant metastasis & $\mathrm{P}^{\mathrm{a}}$ \\
\hline \multicolumn{5}{|l|}{ CMYC (90) } \\
\hline Normal & $24 / 24(100 \%)$ & $14 / 15(93 \%)$ & $49 / 51(96 \%)$ & 0.49 \\
\hline Amplification & $0 / 24(0 \%)$ & $1 / 15(7 \%)$ & $2 / 51(4 \%)$ & \\
\hline \multicolumn{5}{|l|}{ MDM2 (94) } \\
\hline Normal & $22 / 22(100 \%)$ & 17/17 (100\%) & $50 / 55(91 \%)$ & 0.05 \\
\hline Amplification & $0 / 22(0 \%)$ & $0 / 17(0 \%)$ & $5 / 55(9 \%)$ & \\
\hline \multicolumn{5}{|l|}{ HER2 (81) } \\
\hline Normal & $20 / 20(100 \%)$ & $17 / 17(100 \%)$ & $44 / 44(100 \%)$ & $\mathrm{NA}^{\mathrm{b}}$ \\
\hline Amplification & $0 / 20(0 \%)$ & $0 / 17(0 \%)$ & $0 / 44(0 \%)$ & \\
\hline \multicolumn{5}{|l|}{ EGFR1 (94) } \\
\hline Normal & $21 / 23(91 \%)$ & 15/16 (94\%) & $53 / 55(96 \%)$ & 0.67 \\
\hline Amplification & $2 / 23(9 \%)$ & $1 / 16(6 \%)$ & $2 / 55(4 \%)$ & \\
\hline \multicolumn{5}{|l|}{ CCND1 (79) } \\
\hline Normal & 19/19 (100\%) & 15/15 (100\%) & $38 / 45(84 \%)$ & 0.05 \\
\hline Amplification & $0 / 19(0 \%)$ & $0 / 15(0 \%)$ & $7 / 45(16 \%)$ & \\
\hline \multicolumn{5}{|l|}{ All genes (97) } \\
\hline Normal & $22 / 24(92 \%)$ & 17/18 (94\%) & $42 / 55(77 \%)$ & 0.09 \\
\hline Amplification & $2 / 24$ (8\%) & 1/18 (6\%) & 13/55 (23\%) & \\
\hline
\end{tabular}

a $\chi^{2}$ test with Pearson's correction.

${ }^{\mathrm{b}} \mathrm{NA}$, not assessed.

Table 3 Association of the polisomies with tumor phenotype

\begin{tabular}{|c|c|c|c|c|c|c|}
\hline & & \multirow[t]{2}{*}{$\mathrm{N}$} & \multicolumn{4}{|c|}{ FISH results } \\
\hline & & & Polisomies (97) & Chr. 8 & Chr. 12 & Chr. 17 \\
\hline \multirow{5}{*}{ Behavior } & Very low risk & 5 & $0 / 3(0 \%)$ & $0 / 3(0 \%)$ & $0 / 2(0 \%)$ & $0 / 3(0 \%)$ \\
\hline & Low risk & 21 & $4 / 21(19 \%)$ & $1 / 21(5 \%)$ & $1 / 21(5 \%)$ & $2 / 20(10 \%)$ \\
\hline & Intermediate risk & 19 & $4 / 18(22 \%)$ & $1 / 15(7 \%)$ & 2/17 (12\%) & $3 / 18(17 \%)$ \\
\hline & High risk & 12 & $1 / 12(8 \%)$ & $0 / 9(0 \%)$ & $1 / 12(8 \%)$ & $0 / 12(0 \%)$ \\
\hline & Malignant+Metastasis & 43 & $13 / 43(30 \%)$ & $1 / 42(2 \%)$ & $5 / 43(12 \%)$ & $7 / 41(17 \%)$ \\
\hline
\end{tabular}

NB: The sum of the polisomies in this table is 24 and not 22 because there are cases with more than one polisomy. 


\section{Sequence Analysis of KIT Gene}

Informative results were obtained in 70 cases; in the remaining cases the quality of DNA was suboptimal. In all, 59 cases showed mutations in KIT gene, namely 56 in exon $11(80 \%)$ and three in exon $9(4.2 \%)$. No mutation was observed in exon 13 and 17. In all, 11 cases were wild-type KIT. Of the 56 cases with mutations in exon 11, $38(68 \%)$ were deletions, $13(23 \%)$ were point mutations, five $(9 \%)$ were insertions. The clinicopathologic characteristics and molecular characteristics of exon11-mutated cases are shown in Table 4. No relationship was found between type of mutation and risk classification $(P=0.3993)$. Cases with deletions however showed a significantly shorter survival than cases with insertions and point mutations $(P=0.0406$, log-rank test, Figure 3$)$. In all, 17 $(45 \%)$ of the 38 deletions involved codons 557-8. In all, 11 of 17 (65\%) were high-risk or clearly malignant tumors, but this result was not significant. In amplified cases, only point mutations and deletions of KIT exon 11 were observed (Table 4), but no relationship was observed between presence and/or type of mutation and presence of amplification. No case showed internal tandem duplications (ITD) corresponding to the duplication described by Lux and Hirota. ${ }^{42,43}$ All three cases with exon 9 mutations had six base pairs insertion at codon 502, which were clinically malignant and localized in the small intestine.

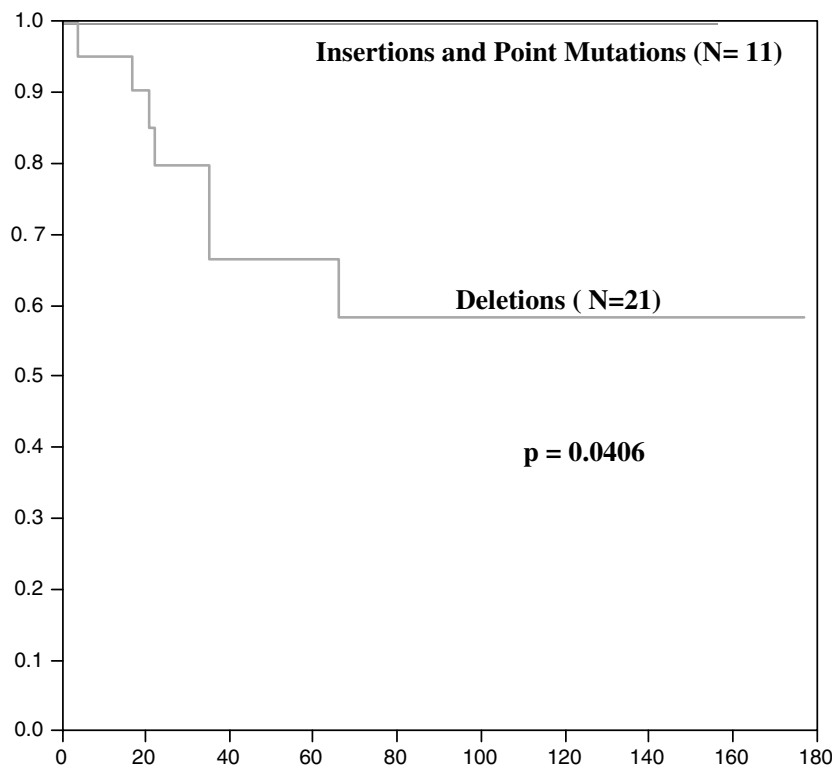

Figure 3 Survival curves according to type of mutation in KITexon-11-mutated cases (Kaplan-Meier method).

Table 4 Association of KIT exon 11 mutation with risk classification and presence of amplifications

\begin{tabular}{|c|c|c|c|c|}
\hline Type of mutation & Del & Ins & Point mutation & $\mathrm{P}^{\mathrm{a}}$ \\
\hline \multicolumn{5}{|l|}{ Risk classification } \\
\hline Low and very low risk & $11 / 38(29 \%)$ & $3 / 5(60 \%)$ & $2 / 13(15 \%)$ & 0.3993 \\
\hline Intermediate risk & 6/38 (16\%) & $1 / 5(20 \%)$ & $3 / 13(23 \%)$ & \\
\hline High risk malignant metastasis & $21 / 38(55 \%)$ & $1 / 5(20 \%)$ & $8 / 13(62 \%)$ & \\
\hline \multicolumn{5}{|l|}{ All genes } \\
\hline Amplification & 6/38 (16\%) & $0 / 5(0 \%)$ & $3 / 13(23 \%)$ & 0.4885 \\
\hline Normal & $32 / 38(84 \%)$ & $5 / 5(100 \%)$ & $10 / 13(77 \%)$ & \\
\hline \multicolumn{5}{|l|}{ CMYC } \\
\hline Amplification & $1 / 37(3 \%)$ & $0 / 4(0 \%)$ & $0 / 12(0 \%)$ & 0.8022 \\
\hline Normal & $36 / 37(97 \%)$ & $4 / 4(100 \%)$ & $12 / 12(12 \%)$ & \\
\hline \multicolumn{5}{|l|}{$M D M 2$} \\
\hline Amplification & $2 / 37(5 \%)$ & $0 / 5(0 \%)$ & $2 / 13(15 \%)$ & 0.3961 \\
\hline Normal & $35 / 37(95 \%)$ & $5 / 5(100 \%)$ & $11 / 13(85 \%)$ & \\
\hline \multicolumn{5}{|l|}{ HER2 } \\
\hline Normal & $32 / 32(100 \%)$ & $4 / 4(100 \%)$ & $13 / 13(100 \%)$ & $\mathrm{NA}^{\mathrm{b}}$ \\
\hline \multicolumn{5}{|l|}{ EGFR1 } \\
\hline Amplification & $2 / 37(5 \%)$ & $0 / 5(5 \%)$ & $0 / 13(0 \%)$ & 0.6036 \\
\hline Normal & $35 / 37(85 \%)$ & $5 / 5(100 \%)$ & $13 / 13(100 \%)$ & \\
\hline \multicolumn{5}{|l|}{ CCND1 } \\
\hline Amplification & $2 / 31(6 \%)$ & $0 / 5(0 \%)$ & $2 / 12(17 \%)$ & 0.4297 \\
\hline Normal & 29/31 (94\%) & $5 / 5(100 \%)$ & $10712(83 \%)$ & \\
\hline
\end{tabular}

a $\chi^{2}$ test with Pearson's correction.

${ }^{\mathrm{b}} \mathrm{NA}$, not assessed.

NB: The total number of amplified cases is nine and not 11 because there are cases with coamplifications. 


\section{Discussion}

The results of this study show that oncogene amplification may be a relevant feature in GIST occurring in at least $10 \%$ of these tumors. Previous studies using CGH and other techniques have already suggested that gross chromosomal aberrations occur frequently in GIST. This includes reports of high-level over-representation of loci at 1q, 8q, and $17 \mathrm{q} \cdot{ }^{33-38,44}$ The present data demonstrate that oncogenes that are known to play a role in various epithelial and mesenchymal tumors can also be amplified in GIST. Among the five oncogenes examined, HER2 was the only one that was never found amplified. $17 q+$ has been reported to be frequently amplified in 'malignant' and metastatic GISTs, but the minimal overlapping region of amplification is $17 q 22$-ter, distal to HER2 locus. ${ }^{38}$ The lack of HER2 alterations fits well with data from Cai et $a l^{45}$ who did not find any immunohistochemically detectable HER2 expression in a series of GIST. All together, these results do not suggest a possible role of trastuzumab (herceptin) therapy. The genes that were found amplified include EGFR1, CCND1, CMYC, and MDM2.

Presence of EGFR1 amplification in five GISTs is of interest. EGFR1 is a transmembraneous receptor kinase protein interacting with HER2. Similar to HER2, EGFR1 serves as a therapeutic target for several new cancer drugs. Our results are consistent with reports suggesting EGFR1 expression in at least a fraction of GIST. ${ }^{45}$ Based on these data, it appears possible that anti-EGFR1 therapies could be another therapeutic alternative in GIST with amplified EGFR1. This is all the more true as the experience from the Her2/Herceptin story seems to suggest that tumors that do not only overexpress a protein but also have a gene amplification might respond particularly well to targeted therapies. ${ }^{46-48}$ An especially important predictive role of gene amplification could be explained by the fact that genes that are overexpressed because of structural DNA damage are more likely to represent a primary (driving) event for the affected cancer cell than overexpression alone. ${ }^{49,50}$ Simple overexpression is more likely to represent a less vital feature of the cell that can be compensated by alternative pathways if EGFR1 is disturbed by interaction with a drug compound. ${ }^{51}$ Moreover, overexpression without detectable DNA damage can always constitute a temporary phenomenon. ${ }^{52}$ We have indeed performed an immunohistochemical staining for EGFR1, but the results did not show any relationship either with prognosis or with amplification.

Amplification of CCND1 and MDM2 were both associated with malignancy. Interestingly, additional FISH analysis of neighboring loci did not show any amplification, suggesting that amplification should be restricted to these two genes. The CCND1 gene, located at $11 \mathrm{q} 13,{ }^{53}$ is coding for a cyclin which is known to be translocated, amplified and overexpressed in many different tumor types including mantle cell lymphoma, head and neck carcinoma, breast carcinoma, hepatocellular carcinoma, and various sarcomas. ${ }^{5-56}$ In GIST it was found in $25 \%$ of the high risk and in $16 \%$ of the malignant tumors but not in 24 very low, low or intermediate-risk tumors. CCND1 amplification may have additional importance as CCND1 has been shown to be essential for malignant transformation in mammary epithelial cells. ${ }^{57}$

MDM2, localized on chromosome 12, has initially been found to be amplified in human sarcomas ${ }^{58}$ and has been proposed as a marker of malignancy in liposarcomas. ${ }^{59}$ It is involved in the Raf/MEK/MAP kinase pathway ${ }^{60}$ and in the phosphatidylinositol 3kinase/AKT/JNK pathway ${ }^{61}$ that are both triggered by KIT activation. ${ }^{62,63}$ In GIST, MDM2 amplification was present in $7 \%$ of the high risk/malignant tumors but absent in 39 very low/low/intermediate-risk tumors. If these results will be confirmed by RNA expression studies, it could be speculated that determination of CCND1 and MDM2 amplification may have clinical utility for the difficult assessment of behavior of GIST. In this case, evaluation of these amplifications could be included in clinical studies dealing with GIST.

CMYC is a well-known oncogene localized on chromosomes $8 \mathrm{q} 24.12-13^{64}$ and amplification has also been described in many different tumor entities. ${ }^{65-68}$ In a previous CGH study, ${ }^{38} 8 \mathrm{q}$ was identified as a frequent site of amplification, above all in 'malignant' GISTs (until 57\% of metastatic tumors). We have found amplification of CMYC only in three cases. That could imply that target of this amplification are other still unknown protooncogenes. Moreover, it should be also kept in mind that comparison with studies published before 2002 is hampered by the lack of universally accepted features suitable to predict the clinical behavior of these tumors. Increased CMYC expression has previously been described in GIST and it has been proposed to include immunohistochemical CMYC analysis in a scoring system to predict the clinical behavior of GISTs together with size and other parameters. ${ }^{69}$ We have not performed immunohistochemical CMYC analysis in this study because in a previous study in bladder cancer we were unable to identify a CMYC antibody that would yield staining results, which show a significant relationship with high-level CMYC amplification (unpublished data). Instability of the MYC protein in formalin-fixed tissues may be the cause for these difficulties.

Interestingly, we found amplifications of multiple genes in four GIST. In three of these cases coamplification of CCND1 and MDM2 was observed. Both genes are related to the RB pathway. MDM2 inhibits the growth regulatory capacity of $\mathrm{RB}$, interacting functionally and physically with it, ${ }^{70}$ while CCND1, through cyclin-dependent kinases, may phosphorilate and inactivate RB. It is tempting to speculate that at least in a subset of GISTs the Rb-CCND1 
pathway may play a key role in the acquisition of the features of malignancy. Apparently, there is a small group of GIST with a high level of genomic instability that are prone to development of genomic amplifications at multiple sites. The role of D-type cyclins in the genesis and progression of GIST is underlined by the recent report of high prevalence of cyclin D3 immunoreactivity in a small series of GISTs. ${ }^{71}$

Using a dual labeling FISH approach also including centromeric probes we also had an opportunity to investigate the prognostic significance of numeric chromosomal aberrations. Cytogenetic alterations in GISTs have previously been extensively studied by CGH and FISH. ${ }^{33-38,44,72}$ From these data it was suggested that GISTs of different grades may reflect a cytogenetic continuum with an increasing number of aberrations. ${ }^{63}$ 'Benign' GISTs often only have an isolated loss of chromosome 14, while intermediaterisk-malignant GISTs have more changes, often including loss of chromosomes $1 \mathrm{p}, 9 \mathrm{p}, 11 \mathrm{p}$ or 22q. ${ }^{33,63}$ Other aberrations, such as deletion of $9 p$ and gains of $8 \mathrm{q}$ and $9 \mathrm{q}$ have been described as associated with malignant GISTs. ${ }^{38}$ Other authors have described, for instance, loss of $13 q$ and gain of a whole chromosome $4{ }^{36}$ correlating it with the behavior of the tumor. In our study, only chromosomes were examined that previously had not been suggested as potential prognostic markers. However, no evidence was found that these changes do have clinical significance.

The use of only one minute tissue sample $(0.6 \mathrm{~mm})$ per tumor has been criticized in the past because of the representativity. Many studies have addressed the question as to whether a higher concordance of TMAs and large section data can be obtained if multiple samples of each tumor are arrayed. As expected, they show that the results obtained on TMAs approach large section results as more samples are being analyzed. ${ }^{73-76}$ However, because large sections contain only a small fraction of the entire tumor mass $(1 / 10000),{ }^{77}$ probably reproducing the findings of large sections is not an optimal end point for the validation of the method. On the contrary, all previously well-established associations between molecular features and clinicopathological end point such as the prognostic importance of ER, PR, p53, and HER2 expression in breast cancer, ${ }^{74,78}$ or Ki67 labeling index in bladder cancer $^{75}$ have been confirmed in TMAs using one spot per tumor. It is probable that the high level of standardization and the greater objectivity of the staining interpretation on one small tissue piece are factors that may compensate for the disadvantage of the small size. ${ }^{77}$

The earlier reported association between KIT exon 11 mutation and tumor prognosis ${ }^{10,21}$ has not been confirmed..$^{25,30,79}$ However, it has been recently claimed that specific types of exon 11 mutations could predict the behavior of the tumor. ${ }^{80-82}$ In our series, tumors showing deletions in KIT exon 11 behaved significantly worse than those with inser- tions or point mutations. This result is in keeping with the recently published data of Miettinen et $a l^{83}$ that have found, in a large series of gastric GISTs, a strong association between deletions in exon 11 and a shorter survival. Most of the deletions involved codons 557-558, and were high-risk and clearly malignant tumors. Even if not significant, this is in agreement with the results of Wardelmann et al, ${ }^{80}$ who have related codon 557-558 deletions to metastatic behavior. Internal tandem duplication (ITD) at the $3^{\prime}$ end have been described as possibly defining a subset of GISTs with favorable course. ${ }^{42,43,81}$ We have not found ITD, maybe due to the relatively small size of our series. The presence of exon 9 mutation has been claimed to be associated with localization in small intestine and malignant behavior. ${ }^{79,82,84,85}$ We found exon 9 mutation in three tumors (six base pairs insertion at codon 502) and they were all localized in the small intestine and clinically malignant (metastatic). No association was found between the type of mutation and the presence of amplifications.

In summary, we have performed a large scale FISH analysis of a series of 94 primary GISTs. Our data suggest that oncogene amplification is a frequent event in a subset of GIST. MDM2 and CCND1 amplification, both occurring in nearly $10 \%$ of the high risk/malignant samples, may have prognostic relevance in GIST.

\section{Acknowledgement}

We thank Ms Hedvika Novotny for excellent technical assistance.

\section{References}

1 Kindblom LG, Remotti HE, Aldenborg F, et al. Gastrointestinal pacemaker cell tumor (GIPACT): gastrointestinal stromal tumors show phenotypic characteristics of the interstitial cells of Cajal. Am J Pathol 1998;152:1259-1269.

2 Miettinen M, Lasota J. Gastrointestinal stromal tumors-definition, clinical, histological, immunohistochemical, and molecular genetic features and differential diagnosis. Virchows Arch 2001;438:1-12.

3 Miettinen M, El-Rifai W, L Sobin HL, et al. Evaluation of malignancy and prognosis of gastrointestinal stromal tumors: a review. Hum Pathol 2002;33:478-483.

4 Fletcher CD, Berman JJ, Corless C, et al. Diagnosis of gastrointestinal stromal tumors: a consensus approach. Hum Pathol 2002;33:459-465.

5 Hirota S, Isozaki K, Moriyama Y, et al. Gain-of-function mutations of c-kit in human gastrointestinal stromal tumors. Science 1998;279:577-580.

6 Huizinga JD, Thuneberg L, Kluppel M, et al. W/kit gene required for interstitial cells of Cajal and for intestinal pacemaker activity. Nature 1995;373:347-349.

7 Sircar K, Hewlett BR, Huizinga JD, et al. Interstitial cells of Cajal as precursors of gastrointestinal stromal tumors. Am J Surg Pathol 1999;23:377-389. 
8 Robinson TL, Sircar K, Hewlett BR, et al. Gastrointestinal stromal tumors may originate from a subset of CD34- positive interstitial cells of Cajal. Am J Pathol 2000;156:1157-1163.

9 Sakurai S, Fukasawa T, Chong JM, et al. C-kit gene abnormalities in gastrointestinal stromal tumors (tumors of interstitial cells of Cajal). Jpn J Cancer Res 1999;90:1321-1328.

10 Singer S, Rubin BP, Lux ML, et al. Prognostic value of KIT mutation type, mitotic activity, and histologic subtype in gastrointestinal stromal tumors. J Clin Oncol 2002;20:3898-3905.

11 Demetri GD. Targeting c-kit mutations in solid tumors: scientific rationale and novel therapeutic options. Semin Oncol 2001;28(5 Suppl 17): 19-26.

12 Demetri GD. Targeting the molecular pathophysiology of gastrointestinal stromal tumors with imatinib. Mechanisms, successes, and challenges to rational drug development. Hematol Oncol Clin North Am 2002;16:1115-1124.

13 Demetri GD, von Mehren M, Blanke CD, et al. Efficacy and safety of imatinib mesylate in advanced gastrointestinal stromal tumors. N Engl J Med 2002;347: 472-480.

14 Heinrich MC, Corless CL, Duensing A, et al. PDGFRA activating mutations in gastrointestinal stromal tumors. Science 2003;299:708-710.

15 Hirota S, Ohashi A, Nishida T, et al. Gain-of-function mutations of platelet-derived growth factor receptor alpha gene in gastrointestinal stromal tumors. Gastroenterology 2003;125:660-667.

16 Rudolph P, Chiaravalli AM, Pauser U, et al. Gastrointestinal mesenchymal tumors-immunophenotypic classification and survival analysis. Virchows Arch 2002;441:238-248.

17 Rudolph P, Gloeckner K, Parwaresch R, et al. Immunophenotype, proliferation, DNA ploidy, and biological behavior of gastrointestinal stromal tumors: a multivariate clinicopathologic study. Hum Pathol 1998;29: 791-800.

18 Taniguchi M, Nishida T, Hirota S, et al. Effect of c-kit mutation on prognosis of gastrointestinal stromal tumors. Cancer Res 1999;59:4297-4300.

19 Emory TS, Sobin LH, Lukes L, et al. Prognosis of gastrointestinal smooth-muscle (stromal) tumors: dependence on anatomic site. Am J Surg Pathol 1999; 23:82-87.

20 Carrillo R, Candia A, Rodriguez-Peralto JL, et al. Prognostic significance of DNA ploidy and proliferative index (MIB-1 index) in gastrointestinal stromal tumors. Hum Pathol 1997;28:160-165.

21 Lasota J, Jasinski M, Sarlomo-Rikala M, et al. Mutations in exon 11 of c-Kit occur preferentially in malignant versus benign gastrointestinal stromal tumors and do not occur in leiomyomas or leiomyosarcomas. Am J Pathol 1999;154:53-60.

22 Hasegawa T, Matsuno Y, Shimoda T, et al. Gastrointestinal stromal tumor: consistent CD117 immunostaining for diagnosis, and prognostic classification based on tumor size and MIB-1 grade. Hum Pathol 2002;33:669-676.

23 Andersson J, Sjogren H, Meis-Kindblom JM, et al. The complexity of KIT gene mutations and chromosome rearrangements and their clinical correlation in gastrointestinal stromal (Pacemaker Cell) tumors. Am J Pathol 2002;160:15-22.
24 Allander SV, Nupponen NN, Ringner M, et al. Gastrointestinal stromal tumors with KIT mutations exhibit a remarkably homogeneous gene expression profile. Cancer Res 2001;61:8624-8628.

25 Corless CL, McGreevey L, Haley A, et al. KIT mutations are common in incidental gastrointestinal stromal tumors one centimeter or less in size. Am J Pathol 2002;160:1567-1572.

26 Crosby JA, Catton CN, Davis A, et al. Malignant gastrointestinal stromal tumors of the small intestine: a review of 50 cases from a prospective database. Ann Surg Oncol 2001;8:50-59.

27 DeMatteo RP, Lewis JJ, Leung D, et al. Two hundred gastrointestinal stromal tumors: recurrence patterns and prognostic factors for survival. Ann Surg 2000;231:51-58.

28 Ernst SI, Hubbs AE, Przygodzki RM, et al. KIT mutation portends poor prognosis in gastrointestinal stromal/smooth muscle tumors. Lab Invest 1998;78: 1633-1636.

29 Hirota S, Isozaki K, Nishida T, et al. Effects of loss-offunction and gain-of-function mutations of c-kit on the gastrointestinal tract. J Gastroenterol 2000;35(Suppl 12):75-79.

30 Rubin BP, Singer S, Tsao C, et al. KIT activation is a ubiquitous feature of gastrointestinal stromal tumors. Cancer Res 2001;61:8118-8121.

31 Heinrich MC, Corless CL, Demetri GD, et al. Kinase mutations and imatinib response in patients with metastatic gastrointestinal stromal tumor. J Clin Oncol 2003;21:4342-4349.

32 Debiec-Rychter M, Dumez H, Judson I, et al. Use of c-KIT/PDGFRA mutational analysis to predict the clinical response to imatinib in patients with advanced gastrointestinal stromal tumours entered on phase I and II studies of the EORTC Soft Tissue and Bone Sarcoma Group. Eur J Cancer 2004;40: 689695.

33 Breiner JA, Meis-Kindblom J, Kindblom LG, et al. Loss of $14 q$ and $22 q$ in gastrointestinal stromal tumors (pacemaker cell tumors). Cancer Genet Cytogenet 2000;120:111-116.

34 Debiec-Rychter M, Sciot R, Pauwels P, et al. Molecular cytogenetic definition of three distinct chromosome arm $14 \mathrm{q}$ deletion intervals in gastrointestinal stromal tumors. Genes Chromosomes Cancer 2001; $32: 26-32$

35 Debiec-Rychter M, Pauwels P, Lasota J, et al. Complex genetic alterations in gastrointestinal stromal tumors with autonomic nerve differentiation. Mod Pathol 2002;15:692-698.

36 Debiec-Rychter M, Lasota J, Sarlomo-Rikala M, et al. Chromosomal aberrations in malignant gastrointestinal stromal tumors: correlation with c-KIT gene mutation. Cancer Genet Cytogenet 2001;128:24-30.

37 Derre J, Lagace R, Terrier P, et al. Consistent DNA losses on the short arm of chromosome 1 in a series of malignant gastrointestinal stromal tumors. Cancer Genet Cytogenet 2001;127:30-33.

38 El-Rifai W, Sarlomo-Rikala M, Andersson LC, et al. DNA sequence copy number changes in gastrointestinal stromal tumors: tumor progression and prognostic significance. Cancer Res 2000;60:3899-3903.

39 Knuutila S, Armengol G, Bjorkqvist AM, et al. Comparative genomic hybridization study on pooled DNAs from tumors of one clinical-pathological entity. Cancer Genet Cytogenet 1998;100:25-30. 
40 Kononen J, Bubendorf L, Kallioniemi A, et al. Tissue microarrays for high-throughput molecular profiling of tumor specimens. Nat Med 1998;4:844-847.

41 Miettinen M, Majidi M, Lasota J. Pathology and diagnostic criteria of gastrointestinal stromal tumors (GISTs): a review. Eur J Cancer 2002;38(Suppl 5):S39-S51.

42 Hirota S, Nishida T, Isozaki K, et al. Gain-of-function mutation at the extracellular domain of KIT in gastrointestinal stromal tumours. J Pathol 2001;193: 505-510.

43 Lux ML, Rubin BP, Biase TL, et al. KIT extracellular and kinase domain mutations in gastrointestinal stromal tumors. Am J Pathol 2000;156:791-795.

44 Sarlomo-Rikala M, El-Rifai W, Lahtinen T, et al. Different patterns of DNA copy number changes in gastrointestinal stromal tumors, leiomyomas, and schwannomas. Hum Pathol 1998;29:476-481.

45 Cai YC, Jiang Z, Vittimberga F, et al. Expression of transforming growth factor-alpha and epidermal growth factor receptor in gastrointestinal stromal tumours. Virchows Arch 1999;435:112-115.

46 Di Leo A, Dowsett M, Horten B, et al. Current status of HER2 testing. Oncology 2002;63(Suppl 1):25-32.

47 Leyland-Jones B. Trastuzumab: hopes and realities. Lancet Oncol 2002;3:137-144.

48 Baselga J. Herceptin alone or in combination with chemotherapy in the treatment of HER2-positive metastatic breast cancer: pivotal trials. Oncology 2001; 61(Suppl 2):14-21.

49 Pauletti G, Godolphin W, Press MF, et al. Detection and quantitation of HER-2/neu gene amplification in human breast cancer archival material using fluorescence in situ hybridization. Oncogene 1996;13: 63-72.

50 Allred DC, Clark GM, Molina R, et al. Overexpression of HER-2/neu and its relationship with other prognostic factors change during the progression of in situ to invasive breast cancer. Hum Pathol 1992;23:974-979.

51 Mendelsohn J, Baselga J. Status of epidermal growth factor receptor antagonists in the biology and treatment of cancer. J Clin Oncol 2003;21: 2787-2799.

52 Baselga J, Hammond LA. HER-targeted tyrosine-kinase inhibitors. Oncology 2002;63(Suppl 1):6-16.

53 Inaba $\mathrm{T}$, Matsushime $\mathrm{H}$, Valentine $\mathrm{M}$, et al. Genomic organization, chromosomal localization, and independent expression of human cyclin D genes. Genomics 1992; 13:565-574.

54 Hall M, Peters G. Genetic alterations of cyclins, cyclindependent kinases, and Cdk inhibitors in human cancer. Adv Cancer Res 1996;68:67-108.

55 Fritz B, Schubert F, Wrobel G, et al. Microarray-based copy number and expression profiling in dedifferentiated and pleomorphic liposarcoma. Cancer Res 2002; 6:2993-2998.

56 Kim SH, Lewis JJ, Brennan MF, et al. Overexpression of cyclin D1 is associated with poor prognosis in extremity soft-tissue sarcomas. Clin Cancer Res 1998; 4:2377-2382.

$57 \mathrm{Yu}$ Q, Geng Y, Sicinski P. Specific protection against breast cancers by cyclin D1 ablation. Nature 2001; 411:1017-1021.

58 Oliner JD, Kinzler KW, Meltzer PS, et al. Amplification of a gene encoding a p53-associated protein in human sarcomas. Nature 1992;358:80-83.

59 Pilotti S, Della TG, Lavarino C, et al. Molecular abnormalities in liposarcoma: role of MDM2 and
CDK4-containing amplicons at 12q13-22. J Pathol 1998;185:188-190.

60 Ries S, Biederer C, Woods D, et al. Opposing effects of Ras on p53: transcriptional activation of mdm2 and induction of p19ARF. Cell 2000;103:321-330.

61 Mayo LD, Donner DB. A phosphatidylinositol 3kinase/Akt pathway promotes translocation of $\mathrm{Mdm} 2$ from the cytoplasm to the nucleus. Proc Natl Acad Sci USA 2001;98:11598-11603.

62 Linnekin D. Early signaling pathways activated by c-Kit in hematopoietic cells. Int J Biochem Cell Biol 1999;31:1053-1074.

63 Heinrich MC, Rubin BP, Longley BJ, et al. Biology and genetic aspects of gastrointestinal stromal tumors: KIT activation and cytogenetic alterations. Hum Pathol 2002;33:484-495.

64 Takahashi E, Hori T, O’Connell P, et al. Mapping of the MYC gene to band 8q24.12-q24.13 by R-banding and distal to fra(8)(q24.11), FRA8E, by fluorescence in situ hybridization. Cytogenet Cell Genet 1991;57:109-111.

65 Schraml P, Kononen J, Bubendorf L, et al. Tissue microarrays for gene amplification surveys in many different tumor types. Clin Cancer Res 1999;5:19661975.

66 Schneider-Stock R, Boltze C, Jager V, et al. Elevated telomerase activity, c-MYC-, and hTERT mRNA expression: association with tumour progression in malignant lipomatous tumours. J Pathol 2003;199: 517-525.

67 Chan D, Wilson TJ, Xu D, et al. Transformation induced by Ewing's sarcoma associated EWS/FLI-1 is suppressed by KRAB/FLI-1. Br J Cancer 2003;88: 137-145.

$68 \mathrm{He}$ TC, Sparks AB, Rago C, et al. Identification of c-MYC as a target of the APC pathway. Science 1998;281:1509-1512.

69 Panizo-Santos A, Sola I, Vega F, et al. Predicting metastatic risk of gastrointestinal stromal tumors: role of cell proliferation and cell cycle regulatory proteins. Int J Surg Pathol 2000;8:133-144.

70 Xiao ZX, Chen J, Levine AJ, et al. Interaction between the retinoblastoma protein and the oncoprotein MDM2. Nature 1995;375:694-698.

71 Pruneri G, Mazzarol G, Fabris S, et al. Cyclin D3 immunoreactivity in gastrointestinal stromal tumors is independent of cyclin D3 gene amplification and is associated with nuclear p27 accumulation. Mod Pathol 2003;16:886-892.

72 Kim MK, Higgins J, Cho EY, et al. Expression of CD34, bcl-2, and kit in inflammatory fibroid polyps of the gastrointestinal tract. Appl Immunohistochem Mol Morphol 2000;8:147-153.

73 Nocito A, Bubendorf L, Maria Tinner E, et al. Microarrays of bladder cancer tissue are highly representative of proliferation index and histological grade. J Pathol 2001;194:349-357.

74 Torhorst J, Bucher C, Kononen J, et al. Tissue microarrays for rapid linking of molecular changes to clinical endpoints. Am J Pathol 2001;159:2249-2256.

75 Moch H, Schraml P, Bubendorf L, et al. Highthroughput tissue microarray analysis to evaluate genes uncovered by cDNA microarray screening in renal cell carcinoma. Am J Pathol 1999;154:981-986.

76 Simon R, Nocito A, Hubscher T, et al. Patterns of her-2/ neu amplification and overexpression in primary and metastatic breast cancer. J Natl Cancer Inst 2001;93: 1141-1146. 
77 Sauter G, Simon R, Hillan K. Tissue microarrays in drug discovery. Nat Rev Drug Discov 2003;2:962-972.

78 Barlund M, Forozan F, Kononen J, et al. Detecting activation of ribosomal protein S6 kinase by complementary DNA and tissue microarray analysis. J Natl Cancer Inst 2000;92:1252-1259.

79 Corless CL, Fletcher JA, Heinrich MC. Biology of gastrointestinal stromal tumors. J Clin Oncol 2004;22: 3813-3825.

80 Wardelmann E, Losen I, Hans V, et al. Deletion of Trp557 and Lys-558 in the juxtamembrane domain of the c-kit protooncogene is associated with metastatic behavior of gastrointestinal stromal tumors. Int J Cancer 2003;106:887-895.

81 Lasota J, Dansonka-Mieszkowska A, Stachura T, et al. Gastrointestinal stromal tumors with internal tandem duplications in $3^{\prime}$ end of KIT juxtamembrane domain occur predominantly in stomach and generally seem to have a favorable course. Mod Pathol 2003;16:1257-1264.
82 Antonescu CR, Sommer G, Sarran L, et al. Association of KIT exon 9 mutations with nongastric primary site and aggressive behavior: KIT mutation analysis and clinical correlates of 120 gastrointestinal stromal tumors. Clin Cancer Res 2003;9: 3329-3337.

83 Miettinen M, Sobin LH, Lasota J. Gastrointestinal stromal tumors of the stomach: a clinicopathologic, immunohistochemical, and molecular genetic study of 1765 cases with long-term follow-up. Am J Surg Pathol 2005;29:52-68.

84 Chen LL, Trent JC, Wu EF, et al. A missense mutation in KIT kinase domain 1 correlates with imatinib resistance in gastrointestinal stromal tumors. Cancer Res 2004;64:5913-5919.

85 Lasota J, Kopczynski J, Sarlomo-Rikala M, et al. KIT 1530ins6 mutation defines a subset of predominantly malignant gastrointestinal stromal tumors of intestinal origin. Hum Pathol 2003;34:1306-1312. 